\title{
Acute kidney injury following aortic valve replacement in patients without chronic kidney disease
}

\section{Moriyama, Noriaki}

2021-01

Moriyama , N , Laakso , T , Raivio , P , Dahlbacka , S , Kinnunen , E-M , Juvonen , T , Valtola , A , Husso , A , Jalava , M P , Ahvenvaara , T , Tauriainen , T, Piuhola , J , Lahtinen , A , Niemelä , M , Mäkikallio , T , Virtanen, M , Maaranen , P, Eskola , M , Savontaus , M , Airaksinen , J , Biancari , F \& Laine, M 2021, ' Acute kidney injury following aortic valve replacement in patients without chronic kidney disease ' , Canadian Journal of Cardiology , vol. 37 , no. 1 , pp. 37-46 . https://doi.org/10.1016/j.cjca.2020.03.015

http://hdl.handle.net/10138/328204

https://doi.org/10.1016/j.cjca.2020.03.015

cc_by_nc_nd

acceptedVersion

Downloaded from Helda, University of Helsinki institutional repository.

This is an electronic reprint of the original article.

This reprint may differ from the original in pagination and typographic detail.

Please cite the original version. 


\section{Journal Pre-proof}

Acute kidney injury following aortic valve replacement in patients without chronic kidney disease

Noriaki Moriyama, MD, Teemu Laakso, MD, Peter Raivio, MD, PhD, Sebastian Dahlbacka, MD, PhD, Eeva-Maija Kinnunen, MD, PhD, Tatu Juvonen, MD, PhD, Antti Valtola, MD, Annastiina Husso, MD, PhD, Maina P. Jalava, MD, Tuomas Ahvenvaara, MD, Tuomas Tauriainen, MD, PhD, Jarkko Piuhola, MD, PhD, Asta Lahtinen, MD, Matti Niemelä, MD, PhD, Timo Mäkikallio, MD, PhD, Marko Virtanen, MD, Pasi Maaranen, MD, Markku Eskola, MD, PhD, Mikko Savontaus, MD, PhD, Juhani Airaksinen, MD, PhD, Fausto Biancari, MD, PhD, Mika Laine, MD, PhD

PII: S0828-282X(20)30270-1

DOI: $\quad$ https://doi.org/10.1016/j.cjca.2020.03.015

Reference: $\quad$ CJCA 3670

To appear in: Canadian Journal of Cardiology

Received Date: 16 January 2020

Revised Date: 25 February 2020

Accepted Date: 14 March 2020

Please cite this article as: Moriyama N, Laakso T, Raivio P, Dahlbacka S, Kinnunen E-M, Juvonen T, Valtola A, Husso A, Jalava MP, Ahvenvaara T, Tauriainen T, Piuhola J, Lahtinen A, Niemelä M, Mäkikallio T, Virtanen M, Maaranen P, Eskola M, Savontaus M, Airaksinen J, Biancari F, Laine M, Acute kidney injury following aortic valve replacement in patients without chronic kidney disease, Canadian Journal of Cardiology (2020), doi: https://doi.org/10.1016/j.cjca.2020.03.015.

This is a PDF file of an article that has undergone enhancements after acceptance, such as the addition of a cover page and metadata, and formatting for readability, but it is not yet the definitive version of record. This version will undergo additional copyediting, typesetting and review before it is published in its final form, but we are providing this version to give early visibility of the article. Please note that, during the production process, errors may be discovered which could affect the content, and all legal disclaimers that apply to the journal pertain.

(C) 2020 Published by Elsevier Inc. on behalf of the Canadian Cardiovascular Society. 


\section{Acute kidney injury following aortic valve replacement in patients without chronic kidney disease}

Noriaki Moriyama, ${ }^{\mathrm{a}} \mathrm{MD}$; Teemu Laakso, ${ }^{\mathrm{a}} \mathrm{MD}$; Peter Raivio, ${ }^{\mathrm{a}} \mathrm{MD}, \mathrm{PhD}$; Sebastian Dahlbacka, ${ }^{\mathrm{a}} \mathrm{MD}$, $\mathrm{PhD}$; Eeva-Maija Kinnunen, ${ }^{\mathrm{a}} \mathrm{MD}, \mathrm{PhD}$; Tatu Juvonen, ${ }^{\mathrm{a}} \mathrm{MD}, \mathrm{PhD}$; Antti Valtola, ${ }^{\mathrm{b}} \mathrm{MD}$; Annastiina Husso, ${ }^{\mathrm{b}} \mathrm{MD}$, PhD; Maina P. Jalava, ${ }^{\mathrm{c}} \mathrm{MD}$; Tuomas Ahvenvaara, ${ }^{\mathrm{d}} \mathrm{MD}$; Tuomas Tauriainen, ${ }^{\mathrm{d}} \mathrm{MD}, \mathrm{PhD}$; Jarkko Piuhola, ${ }^{\mathrm{e}} \mathrm{MD}$, PhD; Asta Lahtinen, ${ }^{\mathrm{e}} \mathrm{MD}$; Matti Niemelä, ${ }^{\mathrm{e}} \mathrm{MD}$, PhD; Timo Mäkikallio, ${ }^{\mathrm{e}} \mathrm{MD}$,

PhD; Marko Virtanen, ${ }^{\mathrm{f}} \mathrm{MD}$; Pasi Maaranen, ${ }^{\mathrm{f}} \mathrm{MD}$; Markku Eskola, ${ }^{\mathrm{f}} \mathrm{MD}, \mathrm{PhD}$; Mikko Savontaus, ${ }^{\mathrm{c}} \mathrm{MD}$, $\mathrm{PhD}$; Juhani Airaksinen, ${ }^{\mathrm{c}} \mathrm{MD}, \mathrm{PhD}$; Fausto Biancari, ${ }^{\mathrm{c}, \mathrm{d}} \mathrm{MD}, \mathrm{PhD}$; Mika Laine, ${ }^{\mathrm{a}} \mathrm{MD}, \mathrm{PhD}$

${ }^{a}$ Heart and Lung Center, Helsinki University Hospital, Helsinki; ${ }^{b}$ Heart Center, Kuopio University Hospital, Kuopio; ${ }^{c}$ Heart Center, Turku University Hospital and University of Turku, Turku; ${ }^{\mathrm{d}}$ Department of Surgery, Oulu University Hospital and University of Oulu, Oulu; ${ }^{\mathrm{e}}$ Department of Internal Medicine, Oulu University Hospital, Oulu; ${ }^{\mathrm{f}}$ Heart Hospital, Tampere University Hospital and University of Tampere, Tampere, Finland.

Short title: AKI in patients without CKD following TAVR and SAVR

\section{Word counts: 5497}

\section{Address for correspondence:}

Mika Laine, MD, PhD, Adjunct Professor of Cardiology

Heart and Lung Center, Helsinki University and Helsinki University Central Hospital, Haartmaninkatu 4, 00290, Helsinki, Finland.

Telephone: +358504279008, Fax: +358504270352, E-mail: Mika.Laine@ hus.fi 


\section{Abstract}

Backgrounds: The data on acute kidney injury (AKI) in patients without chronic kidney disease (CKD) after transcatheter aortic valve replacement (TAVR) are limited. The study sought to compare the incidence of AKI and its impact on 5-year mortality following TAVR and surgical aortic valve replacement (SAVR) in patients without CKD.

Methods: This registry included data from 6463 consecutive patients who underwent TAVR or SAVR. CKD was defined as estimated glomerular filtration rate (eGFR) $<60 \mathrm{ml} / \mathrm{min} / 1.73 \mathrm{~m}^{2}$. AKI was defined according to the Kidney Disease Improving Global Outcomes criteria. For sensitivity analysis, propensity-score (PS) matching between TAVR and SAVR was performed.

Results: The study included 4555 consecutive patients (TAVR, $n=1215$ and SAVR, $n=3340$ ) without CKD. PS matching identified 542 pairs. Patients who underwent TAVR had a significantly lower incidence of AKI in comparison to those who underwent SAVR (unmatched $4.7 \%$ vs $16.4 \%, P<0.001$, multivariable analysis: OR $0.29,95 \%$ CI $0.20-0.41$; matched $5.9 \%$ vs $19.0 \%, P<0.001)$. Patients with AKI had significantly increased 5-year mortality compared to those without AKI (unmatched 36.0\% vs $19.1 \%, \log$-rank $P<0.001$; matched $36.3 \%$ vs $24.0 \%$, log-rank $P<0.001)$. The adjusted hazard ratios for 5-year mortality were 1.58 (95\%CI 1.20-2.08) for AKI grade 1, 3.27 (95\%CI 2.09-5.06) for grade 2 and $4.82(95 \% \mathrm{CI} 2.93-8.04)$ for grade 3. 
Conclusions: TAVR in patients without CKD was associated with significantly less frequent incidence of AKI compared with SAVR. AKI significantly increased the risk of 5-year mortality after either TAVR or SAVR and increasing severity of AKI was incrementally associated with 5-year mortality.

Clinical Trial Registration: ClinicalTrials.gov, Identifier: NCT03385915.

(URL https://clinicaltrials.gov/ct2/show/NCT03385915) 


\section{Brief summary}

From the nationwide registry, 4555 consecutive patients with pre-procedural normal kidney function who underwent TAVR and SAVR (TAVR, n=1215 and SAVR, n=3340) were evaluated. Our findings demonstrated that patients who underwent TAVR had a significantly lower incidence of AKI in comparison to those who underwent SAVR, and TAVR was associated with decreasing incidence of AKI during study periods. AKI was significantly associated with increased risk of 5-year mortality, correlating with its severity. 


\section{Introduction}

Acute kidney injury (AKI) is a common complication in patients undergoing transcatheter aortic valve replacement (TAVR) and surgical aortic valve replacement (SAVR), its incidence ranging up to $56 \%$ depending on the population. ${ }^{1-7}$ Patients with pre-procedural chronic kidney disease (CKD) who develop AKI have higher risk of early and late adverse events. ${ }^{3,6,8}$ TAVR has become the preferred treatment strategy for severe aortic valve stenosis (AS) in patients at high and intermediate risk with a high prevalence of $\mathrm{CKD}^{3,9,10}$ and the incidence and clinical impact of AKI have been well documented in patients with CKD. ${ }^{11,12}$ During the past few years, the clinical practice with TAVR has shifted towards treating lower-risk patients deemed to have less frequent pre-procedural CKD. ${ }^{1,13-16}$ However, limited data exist on the occurrence and prognosis of AKI following TAVR in patients without CKD. Accordingly, knowledge of AKI and its impact on late outcomes in this subset of patients are essential before expanding the indication for TAVR to lower-risk patients with long life expectancy. Therefore, we sought to investigate 1) the incidence and predictors of AKI, and 2) 5-year mortality in patients without pre-procedural CKD underwent TAVR or SAVR and 3) the impact of AKI and its severity on 5-year mortality. 


\section{Material and methods}

\section{Study design}

The FinnValve registry is a nationwide registry, which includes retrospectively collected data from consecutive and unselected patients who underwent TAVR or SAVR with a bioprosthesis from 2008 to 2017 in Finland. ${ }^{17}$ This study was approved by the Institutional Review Boards of each participating center. The inclusion and exclusion criteria for the study entry are shown in Supplementary Table S1. The operative risk of the patients was evaluated according to the Society of Thoracic Surgeons (STS) ${ }^{18}$ and the EuroSCORE II ${ }^{19}$ risk scoring methods. For the purpose of the current analysis, patients with baseline estimated glomerular filtration rate $(\mathrm{eGFR})<60 \mathrm{ml} / \mathrm{min} / 1.73 \mathrm{~m}^{2}$ according to the Modification of Diet in Renal Disease (MDRD) equation ${ }^{20}$ and dialysis were excluded.

\section{Definition criteria of baseline risk factors}

Baseline variables were defined according to the EuroSCORE II criteria. ${ }^{19}$ Stratification of the severity of CKD was performed eGFR using the MDRD equation. ${ }^{20}$ CKD has 5 stages, organized by eGFR ( tage $1=\mathrm{eGFR}>90 \mathrm{ml} / \mathrm{min} / 1.73 \mathrm{~m}^{2}$, stage2=eGFR 60 to 89 , stage $3=\mathrm{eGFR} 30$ to 59 , stage4=eGFR 15 to 29 , stage $5=\mathrm{eGFR}<15) .{ }^{21}$ CKD is typically not clinically evident until eGFR falls 
below $60 \mathrm{ml} / \mathrm{min} / 1.73 \mathrm{~m}^{2}$. Therefore, clinically normal kidney function was defined as

$\mathrm{eGFR} \geq 60 \mathrm{ml} / \mathrm{min} / 1.73 \mathrm{~m}^{2}$. Other comorbidities were defined in the previous literature. ${ }^{17}$

\section{Patient selection}

The registry includes data on 6463 patients who underwent TAVR or SAVR. Pertinent to the present analysis, patients with CKD ( $\mathrm{n}=1907)$ and those with missing values of serum creatinine $(\mathrm{n}=1)$ were excluded. In 4555 patients (TAVR:n=1215; SAVR:n=3340) without CKD, a propensity-score (PS) matching between TAVR and SAVR groups was developed for comparative outcome analysis (Figure 1A).

\section{Outcome measures}

The primary outcome of this study was to elucidate the incidence of post-operative AKI. The secondary outcomes were predictors of AKI, 5-year all-cause mortality in patients with or without AKI and impact of AKI on 5-year mortality. Moreover, the effect of AKI severity on 5-year mortality was evaluated by multivariate analysis. In the unmatched cohort, the incidence and predictors of AKI, and 5-year all-cause mortality in patients with or without AKI was evaluated. In the matched cohort, the incidence of AKI was evaluated for the purpose of sensitivity analysis and 5-year all-cause mortality between TAVR and SAVR was analyzed. 
AKI was defined according to the KDIGO criteria, ${ }^{22}$ because it considers a time frame for creatinine changes of seven days, which usually is the average length of hospital day in patients undergoing SAVR (Supplementary Table S2). Definition criteria of the other outcomes are summarized in Supplementary Table S3. ${ }^{23,24}$

\section{Statistical analysis}

Categorical variables were presented as counts and/or percentages and were compared using the chi-square test. Continuous variables were presented as the mean \pm standard deviation or median and interquartile range $\left(25^{\text {th }}-75^{\text {th }} \mathrm{IQR}\right)$ and were compared using the Student's t-test or the Wilcoxon rank sum test based on their distributions. We identified a matched cohort of TAVR and SAVR patients to account for potential differences in baseline characteristics. One-to-one PS matching was performed employing the nearest neighbour method and a caliper width of 0.2 of the standard deviation of the logit of the estimated propensity score. Absolute standardized differences lower than 0.10 were considered an acceptable imbalance between the treatment groups. The detailed description of a PS matching is shown in Supplementary Table S4 and Supplementary Figure S1. Early outcomes in the matched series were evaluated using the t-test for paired samples for continuous variables and the McNemar test for dichotomous variables. These tests were used to evaluate any difference in the adverse events of matched pairs. Trends for the incidence of AKI over time was analyzed using the 
Mantel-Haenszel linear-by-linear association chi-square test for trend. Differences in the long-term survival were evaluated by the Kaplan-Meier method with the log-rank test. Covariates including all baseline and procedural characteristics and early outcomes exhibiting a $P$ value $<0.10$ in the univariate analysis were included in a logistic regression analysis to determine the predictive factors of the incidence of AKI, and 5-year all-cause mortality in the unmatched cohort. A $P<0.05$ was set for statistical significance for all tests. Statistical analysis was performed using JMP 10.0 (SAS Institute Inc, Cary, NC), and SPSS 22.0 (IBM Corporation, New York, USA). 


\section{Results}

\section{Patient characteristics and early outcomes}

A total of 4555 patients without pre-procedural CKD were the subjects of this analysis

(Figure 1A). The mean follow-up was 3.5 \pm 2.6 years (median3.0, IQR1.3-5.2, range 0-10.0 years) in the overall cohorts. The distribution of baseline eGFR is illustrated in Figure 1B. In the unmatched cohort, TAVR patients in comparison to SAVR patients were older and more often female, and had a higher predicted risk of operative mortality (Table 1). During the study period, the proportion of SAVR decreased, whereas that of TAVR increased $\left(P_{\text {trend }}<0.001\right)$ (Supplementary Figure S2). After PS matching, 542 matched pairs of patients who underwent TAVR or SAVR were identified (Table 2 and Supplementary Figure S1). The procedural characteristics and early outcomes are summarized in Table 3. Among the unmatched and matched series, patient who underwent TAVR had significantly lower bleeding complications according to life-threatening/disabling or major bleeding and the E-CABG bleeding grades 2-3, but similar 30-day mortality compared to those who underwent SAVR.

\section{Incidence and predictors of AKI}

During the index hospitalization, $13.3 \%, 4.3 \%$ and $1.3 \%$ of patients in the unmatched series and $12.5 \%, 5.9 \%$ and $1.7 \%$ of those in the matched series developed AKI, AKI grade $\geq 2$ and dialysis, respectively (Figure 2). Patients who underwent TAVR had a significantly lower incidence of AKI in 
comparison to those who underwent SAVR (unmatched: $4.7 \%$ vs $16.4 \%, P<0.001$; matched: $5.9 \%$ vs $19.0 \%, P<0.001)$. In the unmatched series, the proportion of AKI in patients who underwent TAVR significantly decreased during the study period $\left(P_{\text {trend }}<0.001\right)$, but not in those who underwent SAVR $\left(P_{\text {trend }}=0.23\right)$ (Supplementary Figure S3).

The results of multivariable analysis performed to identify predictors of AKI are shown in Table 4 and Supplementary Table S5. TAVR (OR:0.29, 95\%CI:0.20-0.41) was independently associated with the less frequent incidence of AKI. In TAVR cohort, timeframe of TAVR (OR:0.52, 95\%CI:0.39-0.61), E-CABG bleeding grade2-3 (OR:9.94. 95\%CI: 3.82-27.0) and paravalvular leakage (PVL) $\geq$ moderate (OR:4.12, 95\%CI: 1.39-10.7) were significantly associated with incidence of AKI. In SAVR cohort, the timeframe of AVR was not associated with the incidence of AKI, while E-CABG bleeding grade2-3 (OR:3.71. 95\%CI: 1.94-3.28) was significantly associated with AKI as with TAVR cohort. Throughout these cohorts, bleeding complications were significantly associated with higher rates of AKI. The incidence of AKI was significantly increasing according to the severity of bleeding based on VARC-2 and E-CABG grade and increased units of RBC transfusion both in TAVR and SAVR cohort $(P<0.001$, respectively). Among patients without bleeding complications and RBC transfusion, patients who underwent TAVR had a significantly lower incidence of AKI in comparison to patients who underwent SAVR (Table 5). 


\section{The effect of AKI on 5-years outcomes}

Cumulative 5-year mortalities following TAVR or SAVR are displayed in Supplementary

Figure S4. In the unmatched series, 5-year mortality significantly differed between the study groups

(TAVR, $40.5 \%$ vs SAVR, $18.3 \%$, log-rank $P<0.001)$. However, no difference was observed in the

matched series (TAVR, 31.5\% vs SAVR, 24.6\%, log-rank $P=0.21$ ).

Kaplan-Meier analysis for all-cause mortality between patients with and those without AKI

in the unmatched is displayed in Figure 3. There were significant differences between patients with

and without AKI on all-cause mortality at 5 years (AKI, 36.0\% vs non-AKI, 19.1\%, log-rank $P<0.001$ )

(Figure 3A). Landmark analysis showed significantly different mortality rates from 3 months to 5

years (AKI, $25.8 \%$ vs non-AKI, $17.1 \%$, log-rank $P=0.004$ ). AKI significantly increased mortality

when compared with non-AKI across the subgroups (TAVR: $68.7 \%$ vs $38.7 \%$, log-rank $P<0.001$ and

SAVR: $36.0 \%$ vs 19.1\%, respectively) (Figure 3B and C). In multivariable analysis, AKI was

significantly associated with increased 5-year mortality (Table 5 and Supplementary Table S6).

In Kaplan-Meier analysis, higher grades of AKI were associated with an increased 5-year

mortality (Figure 3D - F). Increasing severity of AKI was significantly associated with incremental

risk of 5-year mortality in multivariable analysis (Figure 4).

\section{Discussion}


In the present study, we observed the following notable findings: 1) the incidence of AKI was significantly less frequently observed in patients who underwent TAVR in comparison to those who underwent SAVR; 2) TAVR was independently associated with less frequent incidence of AKI in comparison to SAVR; 3) bleeding complications were significantly associated with AKI following TAVR and SAVR; 4) the proportion of AKI in patients who underwent TAVR significantly decreased during the study period; 5) the presence of AKI was associated with an increased risk of all-cause mortality at 5 years correlating with its severity.

Although several studies have examined the outcomes of AKI in patients with high surgical risk, most have included patients with a high prevalence of CKD, ranging up to $62 \% .^{3,11,25,26}$ In these high-risk subset of patients, the incidence rates of AKI ranged from 12\% to 57\% after TAVR, depending on the definition used. ${ }^{26}$ On the other hand, among patients with intermediate to low surgical risk and lower prevalence of CKD, the incidence of AKI after TAVR decreased to less than $5 \% .^{10,13,14,27,28}$ In the current study, PS matching identified well balanced patients with low to intermediate surgical risk (STS score: $3.1 \pm 1.9$ in TAVR vs. $3.2 \pm 3.1$ in SAVR). Our data shows a comparable rate of AKI after TAVR compared to the previous reports including lower-risk patients.

As previously reported, patients with CKD undergoing SAVR are at significantly higher risk of AKI and hemodialysis. ${ }^{5}$ Gummert JF et al. showed that up to $16 \%$ of patients with CKD following 
SAVR required hemodialysis during the post-operative period. ${ }^{29}$ Although our results show higher incidence of AKI following SAVR compared to current landmark randomized trial, ${ }^{13,14}$ the rate of AKI is comparable to real-world results (15.4\% of SAVR) from the largest representative data including 183,506 patients. ${ }^{6}$ In addition to this, we confirmed that SAVR is associated with a significantly higher risk of AKI compared with TAVR even among patients without CKD. It is worth noting that herein breeding complication was the strongest risk factor for AKI in patients who underwent TAVR and SAVR as previously reported. ${ }^{30}$ The negative effect of bleeding on kidney function could be partially explained by reduced perfusion to kidney. Although bleeding severities stratified by VARC-2, E-CABG and units of RBC transfusion were incrementally associated with the increasing incidence of AKI in both treatment groups, importantly, if no bleeding happens, patients who underwent TAVR had significantly lower incidence of AKI compared with those who underwent SAVR even after PS-matching (Table 5). The invasive nature of SAVR can be considered disadvantageous in terms of kidney function. The effects of cardiopulmonary bypass on kidney function after surgical treatment have been well elucidated. ${ }^{5,31}$ Similarly, the cardiopulmonary bypass time and severe bleeding requiring blood transfusion affected worsening kidney function after SAVR in patients without CKD of the present study. Interestingly, increasing case volume was associated with decreasing the incidence of AKI in TAVR cohort, but not in SAVR (Table 4 and Online Figure 3). The mechanisms 
are likely multifactorial. Refinements in procedural technique, the lower device profile and lower amount contrast used might play an important role in the prevention of AKI as with the reduction of vascular and bleeding complication as reported in previous literatures. ${ }^{32,33}$

A previous report showed that the occurrence of AKI is associated with higher rates of early and 1-year mortality following TAVR. ${ }^{25}$ Among a population at high risk with $50 \%$ of CKD, Elmariah S et al. reported $66.7 \%$ of 1-year mortality in patients with AKI following TAVR, whereas that was $8.6 \%$ in patients who did not develop AKI. ${ }^{34}$ The current study demonstrated that AKI is associated with increased mortality following TAVR. Moreover, in our study, even patients who developed AKI grade 1 was significantly associated with a worse outcome compared to patients without AKI. The minimally invasive nature of TAVR, the usage of minimalist approach such as transfemoral procedure with local anesthesia, the avoidance of cardiopulmonary bypass and the reduced risk of bleeding complications can be considered advantageous in terms of kidney protection.

Several limitations of our analysis should be acknowledged. Firstly, the retrospective nature is the main limitation of this study. Secondly, even though PS matching resulted in sufficient balance of baseline characteristics, bias due to unknown or unmeasured confounders cannot be excluded. Thirdly, we do not have data on renal function after discharge and we cannot estimate the rate of late dialysis. Moreover, we do not have data on preprocedural proteinuria. Therefore, early-stage CKD 
might have been underdiagnosed and included in this study populations. Fourthly, we do not have data on SAVR with a mechanical valve. Therefore, SAVR group in this study might not reflect real-world clinical setting in patients who underwent SAVR with low surgical risk. Finally, the predictors of AKI in TAVR cohort should be interpreted cautiously, because no information on contrast volume administered during TAVR procedures were available for this analysis.

In conclusion, in this nationwide registry, AKI was significantly less frequent after TAVR in comparison to SAVR among patients without clinically evident CKD. Periprocedural bleeding was a strong risk factor for the development of AKI after either TAVR of SAVR. AKI significantly increased the risk of 5-year mortality and increasing severity of AKI was associated with incremental risk of late mortality. Although TAVR could be favorable treatment in terms of risk of AKI for AS patients without CKD in comparison to SAVR, further efforts are needed to reduce the incidence of AKI and to improve the outcomes of patients with AKI following AVR. 
Acknowledgements

None

Funding

None

\section{Disclosure}

None 


\section{References}

1. Thyregod HG, Steinbrüchel DA, Ihlemann N, Nissen H, Kjeldsen BJ, Petursson P, et al. Transcatheter Versus Surgical Aortic Valve Replacement in Patients With Severe Aortic Valve Stenosis: 1-Year Results From the All-Comers NOTION Randomized Clinical Trial. J Am Coll Cardiol. 2015;65:2184-94.

2. Aregger F, Wenaweser P, Hellige GJ, Kadner A, Carrel T, Windecker S, et al. Risk of acute kidney injury in patients with severe aortic valve stenosis undergoing transcatheter valve replacement. Nephrol Dial Transplant. 2009;24:2175-9.

3. Bagur R, Webb JG, Nietlispach F, Dumont E, De Larochellière R, Doyle D, et al. Acute kidney injury following transcatheter aortic valve implantation: predictive factors, prognostic value, and comparison with surgical aortic valve replacement. Eur Heart J. 2010;31:865-74.

4. Elhmidi Y, Bleiziffer S, Piazza N, Hutter A, Opitz A, Hettich I, et al. Incidence and predictors of acute kidney injury in patients undergoing transcatheter aortic valve implantation. Am Heart J. 2011;161:735-9.

5. Karkouti K, Wijeysundera DN, Yau TM, Callum JL, Cheng DC, Crowther M, et al. Acute kidney injury after cardiac surgery: focus on modifiable risk factors. Circulation. 2009;119:495-502.

6. Kumar N, Garg N. Acute kidney injury after aortic valve replacement in a nationally representative cohort in the USA. Nephrol Dial Transplant. 2019;34:295-300.

7. Ternacle J, Côté N, Krapf L, Nguyen A, Clavel MA, Pibarot P. Chronic Kidney Disease and the Pathophysiology of Valvular Heart Disease. Can J Cardiol. 2019;35:1195-1207.

8. Généreux P, Kodali SK, Green P, Paradis JM, Daneault B, Rene G, et al. Incidence and effect of acute kidney injury after transcatheter aortic valve replacement using the new valve academic research consortium criteria. Am J Cardiol. 2013;111:100-5.

9. Leon MB, Smith CR, Mack M, Miller DC, Moses JW, Svensson LG, et al. PARTNER Trial Investigators. Transcatheter aortic-valve implantation for aortic stenosis in patients who cannot undergo surgery. N Engl J Med. 2010;363:1597-607. 
10. Leon MB, Smith CR, Mack MJ, Makkar RR, Svensson LG, Kodali SK, et al. PARTNER 2 Investigators. Transcatheter or Surgical Aortic-Valve Replacement in Intermediate-Risk Patients. N Engl J Med. 2016;374:1609-20.

11. Oguri A, Yamamoto M, Mouillet G, Gilard M, Laskar M, Eltchaninoff H, et al. FRANCE 2 Registry investigators. Impact of chronic kidney disease on the outcomes of transcatheter aortic valve implantation: results from the FRANCE 2 registry. EuroIntervention. 2015;10:e1-9.

12. Allende R, Webb JG, Munoz-Garcia AJ, de Jaegere P, Tamburino C, Dager AE, et al. Advanced chronic kidney disease in patients undergoing transcatheter aortic valve implantation: insights on clinical outcomes and prognostic markers from a large cohort of patients. Eur Heart J. 2014;35:2685-96.

13. Mack MJ, Leon MB, Thourani VH, Makkar R, Kodali SK, Russo M, et al. PARTNER 3 Investigators. Transcatheter Aortic-Valve Replacement with a Balloon-Expandable Valve in Low-Risk Patients. N Engl J Med. 2019;380:1695-1705.

14. Popma JJ, Deeb GM, Yakubov SJ, Mumtaz M, Gada H, O'Hair D, et al. Evolut Low Risk Trial Investigators. Transcatheter Aortic-Valve Replacement with a Self-Expanding Valve in Low-Risk Patients. N Engl J Med. 2019;380:1706-15.

15. Thyregod HGH, Ihlemann N, Jørgensen TH, Nissen H, Kjeldsen BJ, Petursson P, et al. Five-Year Clinical and Echocardiographic Outcomes from the Nordic Aortic Valve Intervention (NOTION) Randomized Clinical Trial in Lower Surgical Risk Patients. Circulation. 2019;139:2714-23.

16. Hansen JW, Foy A, Yadav P, Gilchrist IC, Kozak M, Stebbins A, et al. Death and Dialysis After Transcatheter Aortic Valve Replacement: An Analysis of the STS/ACC TVT Registry. JACC Cardiovasc Interv. 2017;10:2064-75.

17. Moriyama N, Laakso T, Biancari F, Raivio P, Jalava MP, Jaakkola J, et al. Prosthetic valve endocarditis after transcatheter or surgical aortic valve replacement with a bioprosthesis: results from the FinnValve Registry. EuroIntervention. 2019;15:e500-e507.

18. Online STS Adult Cardiac Surgery Risk Calculator. Available at: http://riskcalc.sts.org/stswebriskcalc/calculate. Accessed on February 4, 2019. 
19. Nashef SA, Roques F, Sharples LD, Nilsson J, Smith C, Goldstone AR, et al. EuroSCORE II. Eur J Cardiothorac Surg. 2012:734-744; discussion 744-5.

20. Levey AS, Coresh J, Greene T, Stevens LA, Zhang YL, Hendriksen S, et al. Chronic Kidney Disease Epidemiology Collaboration. Using standardized serum creatinine values in the modification of diet in renal disease study equation for estimating glomerular filtration rate. Ann Intern Med. 2006;145:247-54.

21. Kopple JD. National kidney foundation K/DOQI clinical practice guidelines for nutrition in chronic renal failure. Am J Kidney Dis. 2001;37:S66-70.

22. Kellum JA, Lameire N; KDIGO AKI Guideline Work Group. Diagnosis, evaluation, and management of acute kidney injury: a KDIGO summary (Part 1). Crit Care. 2013;17:204.

23. Mariscalco G, Gherli R, Ahmed AB, Zanobini M, Maselli D, Dalén M, et al. Validation of the European Multicenter Study on Coronary Artery Bypass Grafting (E-CABG) Bleeding Severity Definition. Ann Thorac Surg. 2016;101:1782-8.

24. Kappetein AP, Head SJ, Généreux P, Piazza N, van Mieghem NM, Blackstone EH, et al. Updated standardized endpoint definitions for transcatheter aortic valve implantation: the Valve Academic Research Consortium-2 consensus document. J Am Coll Cardiol. 2012;60:1438-54.

25. Sinning JM, Ghanem A, Steinhäuser H, Adenauer V, Hammerstingl C, Nickenig G, et al. Renal function as predictor of mortality in patients after percutaneous transcatheter aortic valve implantation. JACC Cardiovasc Interv. 2010;3:1141-9.

26. Gilard M, Eltchaninoff H, Iung B, Donzeau-Gouge P, Chevreul K, Fajadet J, et al; FRANCE 2 Investigators. Registry of transcatheter aortic-valve implantation in high-risk patients. N Engl J Med. 2012;366:1705-15.

27. Barbanti M, Gulino S, Capranzano P, Immè S, Sgroi C, Tamburino C, et al. Acute Kidney Injury With the RenalGuard System in Patients Undergoing Transcatheter Aortic Valve Replacement: The PROTECT-TAVI Trial (PROphylactic effecT of furosEmide-induCed diuresis with matched isotonic intravenous hydraTion in Transcatheter Aortic Valve Implantation). JACC Cardiovasc Interv. 2015;8:1595-604.

28. Schymik G, Varsami C, Bramlage P, Conzelmann LO, Würth A, Luik A, et al. Two-Year Outcomes of Transcatheter Compared With Surgical Aortic Valve Replacement in 
"Minimal-Risk" Patients Lacking EuroSCORE Co-morbidities (from the TAVIK Registry). Am J Cardiol. 2018;122:149-55.

29. Gummert JF, Bucerius J, Walther T, Doll N, Falk V, Schmitt DV, et al. Requirement for renal replacement therapy in patients undergoing cardiac surgery. Thorac Cardiovasc Surg. 2004;52:70-6.

30. Konigstein M, Ben-Assa E, Banai S, Shacham Y, Ziv-Baran T, Abramowitz Y, et al. Periprocedural bleeding, acute kidney injury, and long-term mortality after transcatheter aortic valve implantation. Can J Cardiol. 2015;31:56-62.

31. Hix JK, Thakar CV, Katz EM, Yared JP, Sabik J, Paganini EP. Effect of off-pump coronary artery bypass graft surgery on postoperative acute kidney injury and mortality. Crit Care Med. 2006;34:2979-83.

32. Stortecky S, Wenaweser P, Diehm N, Pilgrim T, Huber C, Rosskopf AB, et al. Percutaneous management of vascular complications in patients undergoing transcatheter aortic valve implantation. JACC Cardiovasc Interv. 2012;5:515-524.

33. Barbanti M, Binder RK, Freeman M, Wood DA, Leipsic J, Cheung A, et al. Impact of low-profile sheaths on vascular complications during transfemoral transcatheter aortic valve replacement. EuroIntervention. 2013;9:929-35.

34. Elmariah S, Farrell LA, Daher M, Shi X, Keyes MJ, Cain CH, et al. Metabolite Profiles Predict Acute Kidney Injury and Mortality in Patients Undergoing Transcatheter Aortic Valve Replacement. J Am Heart Assoc. 2016;5:e02712. 


\section{Figure legends}

Figure 1. Study flowchart and distribution of the estimated glomerular filtration rate

(A) Study flow chart.

(B) The right $y$-axis refers to the histogram of the number of patients with estimated glomerular filtration rate (eGFR) per $5 \mathrm{ml} / \mathrm{min} / 1.73^{2}$ increments.

$\mathrm{AKI}=$ acute kidney injury; $\mathrm{CKD}=$ chronic kidney disease; $\mathrm{IQR}=$ interquartile range.

\section{Figure 2. Incidence of AKI following TAVR and SAVR}

Patients who underwent TAVR had a significantly lower incidence of AKI in comparison to patients who underwent SAVR.

Abbreviations as in Table 1 and Figure 1.

Figure 3. Cumulative event curves for 5-year all-cause mortality in patients with or without AKI

(A) Cumulative event curves for all-cause death and landmark analysis from 3 month in total cohort.

(B and C) Cumulative event curves for all-cause mortality (B) in TAVR and (C) in SAVR cohort.

(D-F) Cumulative event curves according to the AKI grades. (D) in total, (E) in TAVR and (F) in SAVR cohort.

*Non-AKI vs AKI grade $1,{ }^{\dagger}$ AKI grade 1 vs AKI grade 2, and ${ }^{\ddagger}$ AKI grade 2 vs AKI grade 3 .

In Figure E, log-rank test was applied to compare the mortality rates only between non-AKI and AKI grade 1 , because of small number of patients with AKI grade 2 and 3. 
Figure 4. The impact of AKI severities on 5-year mortality

AKI grades were significantly associated with a higher incidence of 5-year mortality. HRs were adjusted by baseline characteristics and early outcomes.

$\mathrm{HR}=$ hazard ratio 
Table 1. Baseline characteristics before propensity score matching

\begin{tabular}{|c|c|c|c|c|}
\hline & $\begin{array}{l}\text { TAVR } \\
(n=1215)\end{array}$ & $\begin{array}{l}\text { SAVR } \\
(n=3340)\end{array}$ & $P$ value & $\begin{array}{c}\text { Absolute } \\
\text { standardized difference }\end{array}$ \\
\hline Age, y & $80.6 \pm 6.8$ & $74.4 \pm 6.6$ & $<0.001$ & 0.988 \\
\hline Female & $629(51.8)$ & $1469(44.0)$ & $<0.001$ & 0.157 \\
\hline Body mass index, $\mathrm{kg} / \mathrm{m}^{2}$ & $26.8 \pm 4.7$ & $27.6 \pm 4.7$ & $<0.001$ & 0.170 \\
\hline Diabetes & $313(25.8)$ & $851(25.5)$ & 0.85 & 0.007 \\
\hline COPD & $269(22.1)$ & 493(14.8) & $<0.001$ & 0.189 \\
\hline Atrial fibrillation & $451(37.1)$ & $668(20.0)$ & $<0.001$ & 0.386 \\
\hline Extracardiac arteriopathy & $229(18.9)$ & $371(11.1)$ & $<0.001$ & 0.220 \\
\hline Coronary artery disease & $327(26.9)$ & 1493(44.7) & $<0.001$ & 0.378 \\
\hline Previous PMI & $208(9.8)$ & $174(4.0)$ & $<0.001$ & 0.230 \\
\hline Previous cardiac surgery & $242(19.9)$ & $78(2.3)$ & $<0.001$ & 0.584 \\
\hline Previous PCI & $250(20.6)$ & $311(9.3)$ & $<0.001$ & 0.328 \\
\hline Previous MI & $156(12.8)$ & $432(12.9)$ & 0.93 & 0.003 \\
\hline Previous stroke & 138(11.4) & $201(6.0)$ & $<0.001$ & 0.192 \\
\hline Hemoglobin, mg/L & $127.2 \pm 15.1$ & $133.8 \pm 14.3$ & $<0.001$ & 0.449 \\
\hline $\mathrm{eGFR}, \mathrm{ml} / \mathrm{min} / 1.73 \mathrm{~m}^{2}$ & $80.8 \pm 17.1$ & $83.8 \pm 17.1$ & $<0.001$ & 0.175 \\
\hline LVEF $<51 \%$ & $310(25.5)$ & $627(18.8)$ & $<0.001$ & 0.162 \\
\hline NYHA class 4 & $118(9.7)$ & $302(9.0)$ & 0.49 & 0.024 \\
\hline Frailty GSS $\geq 2$ & $155(12.8)$ & $72(2.2)$ & $<0.001$ & 0.411 \\
\hline
\end{tabular}


Journal Pre-proof

\begin{tabular}{|l|c|c|c|c|}
\hline AHF within 90days & $135(11.1)$ & $353(10.6)$ & 0.60 & 0.016 \\
\hline Urgent/emergent procedure & $79(6.5)$ & $411(12.3)$ & $<0.001$ & 0.200 \\
\hline Associated PCI or CABG & $60(4.9)$ & $1381(41.4)$ & $<0.001$ & 0.960 \\
\hline STS score, \% & $3.8 \pm 2.7$ & $2.6 \pm 2.2$ & $<0.001$ & 0.487 \\
\hline EuroScore II, \% & $5.6 \pm 5.7$ & $3.5 \pm 4.4$ & $<0.001$ & 0.412 \\
\hline Timeframe of AVR & & & $<0.001$ & 0.712 \\
\hline $1^{\text {st }}$ quartile & $43(3.5)$ & $706(21.1)$ & & 0.388 \\
\hline $2^{\text {nd }}$ & $142(11.7)$ & $892(26.7)$ & & 0.094 \\
\hline $3^{\text {rd }}$ & $314(25.8)$ & $1000(30.0)$ & & 0.806 \\
\hline $4^{\text {th }}$ & $716(58.9)$ & $742(22.2)$ & & \\
\hline
\end{tabular}

Values are expressed as counts and percentages (in parentheses), mean \pm standard deviation.

$\mathrm{AHF}=$ acute heart failure; $\mathrm{AVR}=$ aortic valve replacement; $\mathrm{CABG}=$ coronary artery bypass grafting; $\mathrm{COPD}=\mathrm{chronic}$ obstructive pulmonary disease; eGFR=estimated glomerular filtration rate; GSS=geriatric status scale; LVEF=left ventricular ejection fraction; MI=myocardial infarction; NYHA=New York Heart Association; $\mathrm{PCI}=$ percutaneous coronary intervention; PMI=pacemaker implantation; SAVR=surgical aortic valve replacement; STS=Society of Thoracic Surgeons; TAVR=transcatheter aortic valve replacement. 
Table 2. Baseline characteristics after propensity score matching

\begin{tabular}{|c|c|c|c|c|}
\hline & $\begin{array}{l}\text { TAVR } \\
(n=542)\end{array}$ & $\begin{array}{l}\text { SAVR } \\
(n=542)\end{array}$ & $P$ value & $\begin{array}{c}\text { Absolute } \\
\text { standardized difference }\end{array}$ \\
\hline Age, y & $77.8 \pm 7.7$ & $77.9 \pm 5.6$ & 0.96 & 0.015 \\
\hline Female & $284(52.4)$ & $276(50.9)$ & 0.63 & 0.030 \\
\hline Body mass index, $\mathrm{kg} / \mathrm{m}^{2}$ & $27.4 \pm 5.2$ & $27.4 \pm 4.7$ & 0.80 & 0.000 \\
\hline Diabetes & $140(25.8)$ & $142(26.2)$ & 0.89 & 0.009 \\
\hline COPD & $141(26.0)$ & $121(22.3)$ & 0.20 & 0.087 \\
\hline Atrial fibrillation & $156(28.8)$ & $166(30.6)$ & 0.51 & 0.039 \\
\hline Extracardiac arteriopathy & $84(15.5)$ & $86(15.9)$ & 0.87 & 0.011 \\
\hline Coronary artery disease & $127(23.4)$ & $138(25.5)$ & 0.44 & 0.049 \\
\hline Previous PMI & $30(5.5)$ & $34(6.3)$ & 0.61 & 0.034 \\
\hline Previous cardiac surgery & $42(7.8)$ & $46(8.5)$ & 0.66 & 0.026 \\
\hline Previous PCI & $80(14.8)$ & $77(14.2)$ & 0.80 & 0.017 \\
\hline Previous MI & $44(8.1)$ & $52(9.6)$ & 0.34 & 0.053 \\
\hline Previous stroke & $42(7.8)$ & $55(10.5)$ & 0.17 & 0.094 \\
\hline Hemoglobin, mg/L & $129.0 \pm 15.2$ & $129.6 \pm 14.3$ & 0.48 & 0.041 \\
\hline eGFR, $\mathrm{ml} / \mathrm{min} / 1.73 \mathrm{~m}^{2}$ & $82.6 \pm 18.4$ & $82.6 \pm 17.2$ & 0.99 & 0.000 \\
\hline $\mathrm{LVEF}<51 \%$ & $130(24.0)$ & $127(23.4)$ & 0.82 & 0.014 \\
\hline NYHA class 4 & $50(9.2)$ & $55(10.2)$ & 0.61 & 0.031 \\
\hline Frailty GSS $\geq 2$ & $40(7.4)$ & $42(7.8)$ & 0.82 & 0.015 \\
\hline AHF within 90days & $61(11.3)$ & $69(12.7)$ & 0.46 & 0.043 \\
\hline
\end{tabular}


Journal Pre-proof

\begin{tabular}{|c|c|c|c|c|}
\hline Urgent/emergent procedure & $45(8.3)$ & $49(9.0)$ & 0.82 & 0.025 \\
\hline Associated PCI or CABG & $51(9.4)$ & $56(10.3)$ & 0.44 & 0.030 \\
\hline STS score, $\%$ & $3.1 \pm 1.9$ & $3.2 \pm 3.1$ & 0.54 & 0.039 \\
\hline EuroScore II, \% & $4.0 \pm 3.6$ & $4.1 \pm 4.8$ & 0.53 & 0.026 \\
\hline Timeframe of AVR & & & 0.57 & \\
\hline $1^{\text {st }}$ quartile & $32(5.9)$ & $38(7.0)$ & & 0.048 \\
\hline $2^{\text {nd }}$ & $95(17.5)$ & $83(15.3)$ & & 0.059 \\
\hline $3^{\text {rd }}$ & $169(31.2)$ & $183(33.8)$ & & 0.056 \\
\hline $4^{\text {th }}$ & $246(45.4)$ & $238(43.9)$ & & 0.030 \\
\hline
\end{tabular}

All abbreviations as in Table 1. 
Table 3. Procedure characteristics and early outcomes

\begin{tabular}{|c|c|c|c|c|c|c|}
\hline & \multicolumn{3}{|c|}{ Unmatched } & \multicolumn{3}{|c|}{ Matched } \\
\hline & $\begin{array}{c}\text { TAVR } \\
(n=1215)\end{array}$ & $\begin{array}{c}\text { SAVR } \\
(n=3340)\end{array}$ & $P$ value & $\begin{array}{l}\text { TAVR } \\
(n=542)\end{array}$ & $\begin{array}{l}\text { SAVR } \\
(n=542)\end{array}$ & $P$ value \\
\hline Procedure characteristics & & & & & & \\
\hline General anesthesia & $356(29.7)$ & $3340(100)$ & $<0.001$ & $190(35.8)$ & $542(100)$ & $<0.001$ \\
\hline Noradrenalin at anesthesia induction & $255(21.0)$ & $610(18.3)$ & 0.038 & $119(22.0)$ & $135(24.9)$ & 0.25 \\
\hline Transfemoral approach & $1068(87.9)$ & & & $469(86.5)$ & & \\
\hline Pre-balloon dilatation & $671(55.2)$ & & & $344(63.5)$ & & \\
\hline Post-balloon dilatation & 181(14.9) & & & $92(17.0)$ & & \\
\hline Full sternotomy & & $3206(96.4)$ & & - & $491(91.1)$ & \\
\hline Cardiopulmonary bypass time, min & & $128.6 \pm 45.6$ & & - & $120.5 \pm 47.7$ & \\
\hline Early outcomes & & & & & & \\
\hline Major vascular complication & $104(8.6)$ & $51(1.5)$ & $<0.001$ & $53(9.8)$ & $12(2.2)$ & $<0.001$ \\
\hline Life-threatening/disabling or major bleeding & $196(16.3)$ & 1732(51.9) & $<0.001$ & $9(16.6)$ & $285(52.6)$ & $<0.001$ \\
\hline E-CABG bleeding grades $2-3^{*}$ & $49(4.1)$ & $722(21.9)$ & $<0.001$ & $30(5.6)$ & $114(21.4)$ & $<0.001$ \\
\hline $\mathrm{RBC}$ transfusion $>4$ units & $41(3.4)$ & $634(19.3)$ & $<0.001$ & $20(3.7)$ & $122(22.5)$ & $<0.001$ \\
\hline PVL $\geq$ moderate & $45(3.7)$ & $19(0.57)$ & $<0.001$ & $19(3.5)$ & $3(0.55)$ & $<0.001$ \\
\hline Stroke & $31(2.6)$ & $114(3.4)$ & 0.14 & $16(3.0)$ & $21(3.9)$ & 0.40 \\
\hline PMI & $110(9.1)$ & $127(3.8)$ & $<0.001$ & $49(9.0)$ & $31(5.7)$ & 0.037 \\
\hline Sepsis & $7(0.58)$ & $39(1.2)$ & 0.074 & $4(0.74)$ & $8(1.5)$ & 0.25 \\
\hline Length of hospital stay, days & $5.2 \pm 4.5$ & $8.0 \pm 5.8$ & $<0.001$ & $5.7 \pm 5.3$ & $8.3 \pm 5.7$ & $<0.001$ \\
\hline
\end{tabular}


Values are expressed as counts and percentages (in parentheses), or mean \pm standard deviation.

$\mathrm{E}-\mathrm{CABG}=$ The European multicenter study on coronary artery bypass grafting; $\mathrm{PVL}=$ paravalvular leakage; $\mathrm{RBC}=$ red blood cell; Other abbreviations as in Table 1.

* E-CABG bleeding grade 2-3=transfusion of more than 4 units of red blood cells and/or operation for mediastinal or peripheral bleeding. ${ }^{23}$ Other outcomes were reported according to the VARC-2 consensus. ${ }^{24}$ 
Table 4. Multivariable analysis of factors associated with AKI

\begin{tabular}{|c|c|c|c|}
\hline & \multicolumn{3}{|c|}{ Multivariable analysis } \\
\hline Overall & OR & $(95 \% \mathrm{CI})$ & $P$ value \\
\hline TAVR (vs. SAVR) & 0.29 & $0.20,0.41$ & $<0.001$ \\
\hline Female & 0.66 & $0.53,0.82$ & $<0.001$ \\
\hline Body mass index (per $1 \mathrm{~kg} / \mathrm{m}^{2}$ ) & 0.93 & $0.91,0.95$ & $<0.001$ \\
\hline Atrial fibrillation & 1.53 & $1.23,1.90$ & $<0.001$ \\
\hline AHF within 90days & 1.56 & $1.10,2.22$ & 0.029 \\
\hline PVL $\geq$ moderate & 4.06 & $2.00,7.96$ & $<0.001$ \\
\hline Sepsis & 3.36 & $1.63,6.76$ & 0.001 \\
\hline E-CABG bleeding grades2-3 & 3.00 & $2.40,3.75$ & $<0.001$ \\
\hline \multicolumn{4}{|l|}{ TAVR } \\
\hline Timeframe of TAVR (per a quartile) & 0.52 & $0.39,0.61$ & $<0.001$ \\
\hline E-CABG bleeding grade2-3 & 9.94 & $3.82,27.0$ & $<0.001$ \\
\hline PVL $\geq$ moderate & 4.12 & $1.39,10.7$ & 0.013 \\
\hline \multicolumn{4}{|l|}{ SAVR } \\
\hline Age (per 1 year) & 1.02 & $1.01,1.04$ & $<0.001$ \\
\hline Female & 0.65 & $0.51,0.84$ & 0.001 \\
\hline Body mass index & 0.92 & $0.90,0.94$ & $<0.001$ \\
\hline Atrial fibrillation & 1.50 & $1.15,1.93$ & 0.003 \\
\hline AHF within 90days & 1.67 & $1.09,2.56$ & 0.020 \\
\hline NYHA class4 & 1.65 & $1.03,2.64$ & 0.038 \\
\hline
\end{tabular}




\begin{tabular}{|l|c|c|c|}
\hline Cardiopulmonary bypass time(per 10min) & 1.09 & $1.02,1.23$ & $<0.001$ \\
\hline Sepsis & 3.51 & $1.49,8.02$ & 0.005 \\
\hline E-CABG bleeding grades2-3 & 3.71 & $1.94,8.28$ & $<0.001$ \\
\hline
\end{tabular}

Covariates included into these models are shown in Supplementary Table S5.

Abbreviations as in Table 1 and 2. 
Table 5. The incidence of AKI according to the bleeding severities and units of transfusion

\begin{tabular}{|c|c|c|c|c|c|c|}
\hline & \multicolumn{3}{|c|}{ AKI in the unmatched } & \multicolumn{3}{|c|}{ AKI in the matched } \\
\hline & TAVR & SAVR & $P$ value & TAVR & SAVR & $P$ value \\
\hline VARC-2 bleeding & & & & & & \\
\hline None & $27(2.9)$ & $99(8.4)$ & $<0.001$ & $15(3.0)$ & $25(10.4)$ & $<0.001$ \\
\hline Minor & $4(4.2)$ & $53(12.3)$ & 0.019 & $0(0)$ & $12(14.8)$ & 0.003 \\
\hline Major & $9(6.4)$ & $184(17.9)$ & $<0.001$ & $3(3.9)$ & $42(19.7)$ & $<0.001$ \\
\hline Life-threatening or disabling & $17(30.9)$ & $213(30.4)$ & 0.94 & $8(24.2)$ & $56(40.6)$ & 0.07 \\
\hline$(P$ value $)$ & $<0.001$ & $<0.001$ & & $<0.001$ & $<0.001$ & \\
\hline E-CABG bleeding & & & & & & \\
\hline
\end{tabular}




\begin{tabular}{|c|c|c|c|c|c|c|}
\hline Grade $0-1$ & $39(3.3)$ & 298(11.4) & $<0.001$ & $17(2.6)$ & 1(13.9) & $<0.001$ \\
\hline Grade 2-3 & $18(36.7)$ & $251(34.8)$ & 0.78 & $9(34.6)$ & $61(43.0)$ & 0.43 \\
\hline$(P$ value $)$ & $<0.001$ & $<0.001$ & & $<0.001$ & $<0.001$ & \\
\hline \multicolumn{7}{|l|}{ RBC transfusion units } \\
\hline None & $28(2.8)$ & $90(8.2)$ & $<0.001$ & $14(2.5)$ & $19(9.8)$ & $<0.001$ \\
\hline $1-2$ units & $7(5.3)$ & 111(11.6) & 0.03 & $2(2.9)$ & 26(12.9) & 0.02 \\
\hline 3-4 units & $6(15.3)$ & $106(16.2)$ & 0.89 & $2(10.0)$ & $29(20.1)$ & 0.28 \\
\hline$>4$ units & $14(34.2)$ & $242(38.2)$ & 0.60 & $8(34.8)$ & $61(46.2)$ & 0.31 \\
\hline$(P$ value $)$ & $<0.001$ & $<0.001$ & & $<0.001$ & $<0.001$ & \\
\hline
\end{tabular}

Values are expressed as counts and percentages (in parentheses). All abbreviations as in Table 1-4. 
Table 6. Multivariable analysis of factors associated with 5-year mortality

\begin{tabular}{|c|c|c|c|}
\hline \multirow[b]{2}{*}{ Overall } & \multicolumn{3}{|c|}{ Multivariable analysis } \\
\hline & HR & $(95 \% \mathrm{CI})$ & $P$ value \\
\hline TAVR (vs. SAVR) & 1.67 & $1.26,2.22$ & $<0.001$ \\
\hline Age (per 1year) & 1.03 & $1.01,1.06$ & $<0.001$ \\
\hline Female & 1.47 & $1.19,1.81$ & $<0.001$ \\
\hline Diabetes & 1.38 & $1.12,1.70$ & 0.002 \\
\hline COPD & 1.56 & $1.24,1.96$ & $<0.001$ \\
\hline Atrial fibrillation & 1.34 & $1.10,1.64$ & 0.005 \\
\hline $\mathrm{LVEF}<51 \%$ & 1.07 & $1.02,1.61$ & 0.037 \\
\hline Major vascular complication & 2.70 & $1.77,4.07$ & $<0.001$ \\
\hline Stroke & 3.24 & $2.16,4.83$ & $<0.001$ \\
\hline AKI & 2.14 & $1.69,2.67$ & $<0.001$ \\
\hline E-CABG bleeding grades2-3 & 1.62 & $1.27,2.07$ & $<0.001$ \\
\hline \multicolumn{4}{|l|}{ TAVR } \\
\hline Age (per 1year) & 1.02 & $1.01,10.5$ & 0.006 \\
\hline Female & 1.94 & $1.28,3.03$ & 0.003 \\
\hline COPD & 2.41 & $1.57,3.70$ & $<0.001$ \\
\hline LVEF $<51 \%$ & 1.26 & $1.05,1.57$ & $<0.001$ \\
\hline Transfemoral approach & 0.54 & $0.45,0.76$ & $<0.001$ \\
\hline Major vascular complication & 1.91 & $1.01,3.60$ & 0.039 \\
\hline AKI & 2.58 & $1.24,5.32$ & 0.011 \\
\hline E-CABG bleeding grades $2-3$ & 2.95 & $1.29,6.89$ & 0.010 \\
\hline \multicolumn{4}{|l|}{ SAVR } \\
\hline Age (per 1year) & 1.04 & $1.01,1.09$ & $<0.001$ \\
\hline Diabetes & 1.36 & $1.05,1.77$ & 0.021 \\
\hline $\mathrm{LVEF}<51 \%$ & 1.50 & $1.17,2.02$ & 0.008 \\
\hline
\end{tabular}




\begin{tabular}{|l|c|c|c|}
\hline Cardiopulmonary bypass time (per 10min) & 1.01 & $1.00,1.02$ & 0.011 \\
\hline Major vascular complication & 2.44 & $1.16,5.01$ & 0.019 \\
\hline Stroke & 3.04 & $1.83,5.00$ & $<0.001$ \\
\hline AKI & 2.08 & $1.57,2.73$ & $<0.001$ \\
\hline E-CABG bleeding grades2-3 & 1.50 & $1.12,2.01$ & 0.006 \\
\hline
\end{tabular}

Covariates included into these models are shown in Supplementary Table S6.

All abbreviations as in Table 1 and 3. 


\begin{tabular}{|c|c|}
\hline $\begin{array}{c}\text { FinnValve registry } \\
\text { Total: } \mathrm{n}=6463 \\
\text { (TAVR: } \mathrm{n}=2130 / \text { SAVR: } \mathrm{n}=4333 \text { ) }\end{array}$ & \\
\hline & $\begin{array}{ll} & \text { Excluded: } \mathrm{n}=1908 \\
\text { - } & \text { CKD }\left(\text { eGFR }<60 \mathrm{ml} / \mathrm{min} / 1.73 \mathrm{~m}^{2}\right) \text { and Dialysis: } \mathrm{n}=1907 \\
\text { - } & \text { Missing Creatinine data: } \mathrm{n}=1 \\
\end{array}$ \\
\hline $\begin{array}{l}\text { Patients without clinical CKD series } \\
\qquad \begin{array}{c}\text { Total: } \mathrm{n}=4555 \\
\text { (TAVR: } \mathrm{n}=1215 \text { / SAVR: } \mathrm{n}=3340 \text { ) }\end{array}\end{array}$ & $\begin{array}{l}\text { 1:1 Propensity score matching series } \\
\text { 1084 patients without clinical CKD } \\
\text { (TAVR: } n=542 \text { / SAVR: } n=542 \text { ) }\end{array}$ \\
\hline $\begin{array}{ll} & \text { Analysis (Unmatched series) } \\
\text { - } & \text { Incidence of AKI } \\
\text { - } & \text { Predictor of AKI } \\
\text { - } & \text { 5-year outcomes and its predictor }\end{array}$ & $\begin{array}{l}\quad \text { Analysis (Matched series) } \\
\text { - } \quad \text { Incidence of AKI } \\
-\quad 5 \text {-year outcomes comparing TAVR and SAVR } \\
\end{array}$ \\
\hline
\end{tabular}




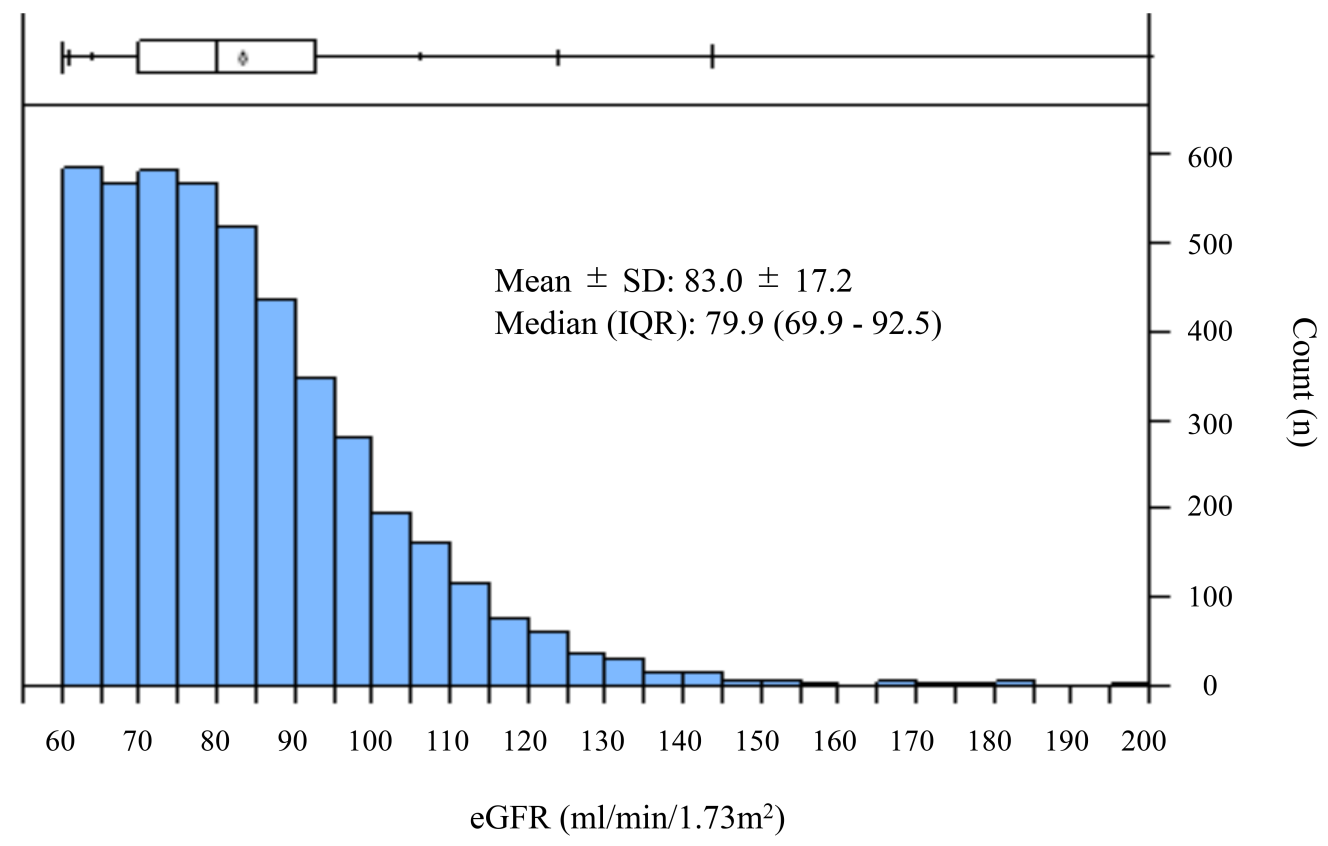




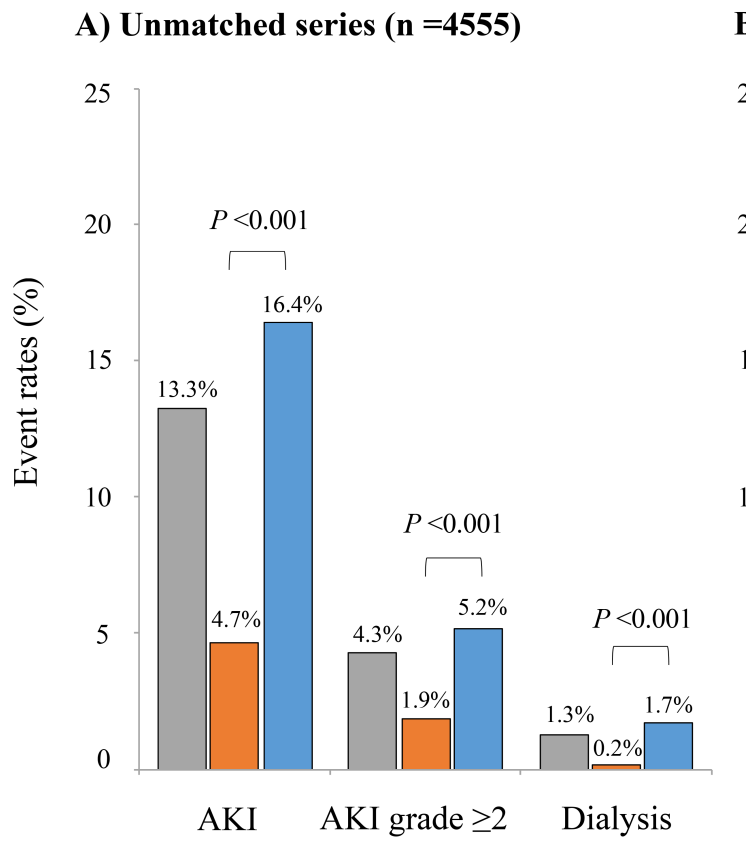

B) Matched series $(\mathrm{n}=1084)$
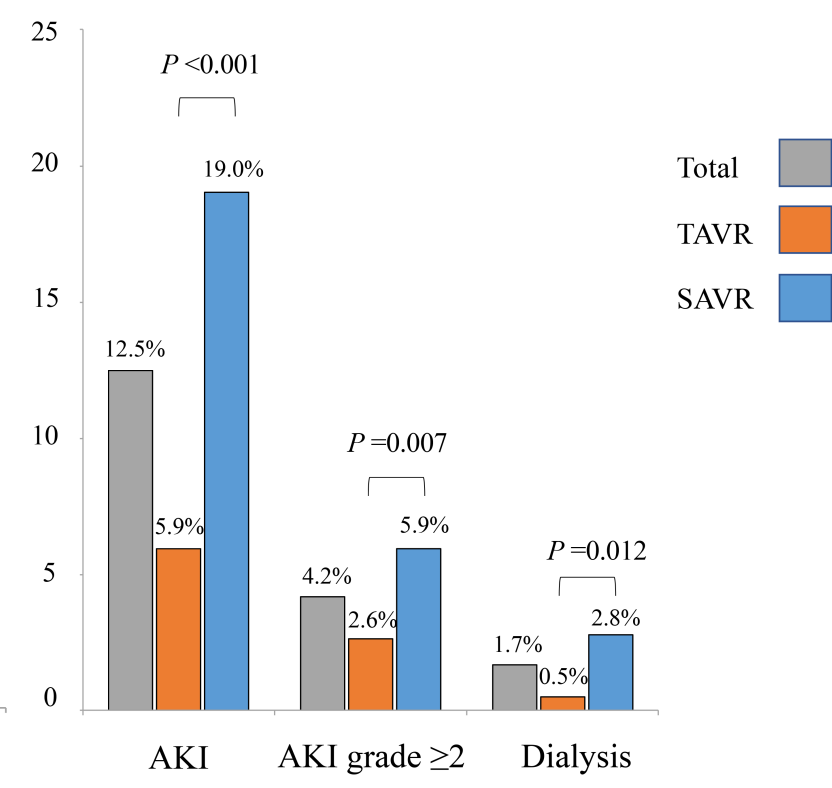


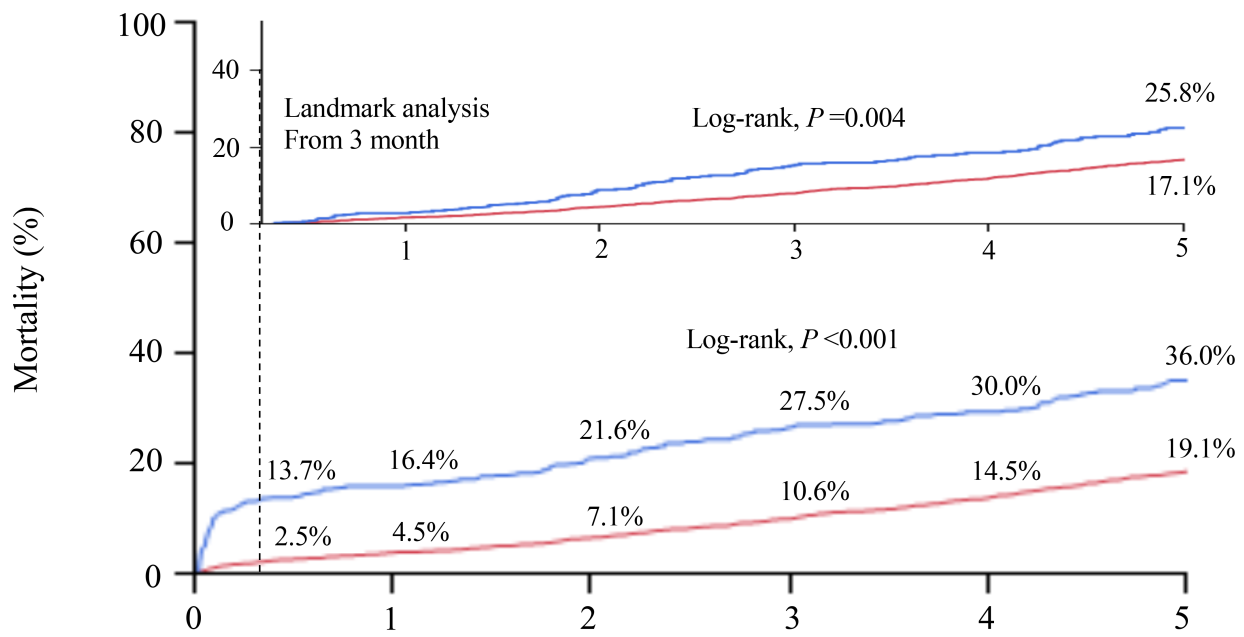

Number at risk:

Time (years)

Non-AKI

\begin{tabular}{|c|c|c|c|c|c|}
\hline 606 & 475 & 403 & 319 & 262 & 285 \\
\hline 3949 & 3287 & 2664 & 2118 & 1639 & 1201 \\
\hline
\end{tabular}




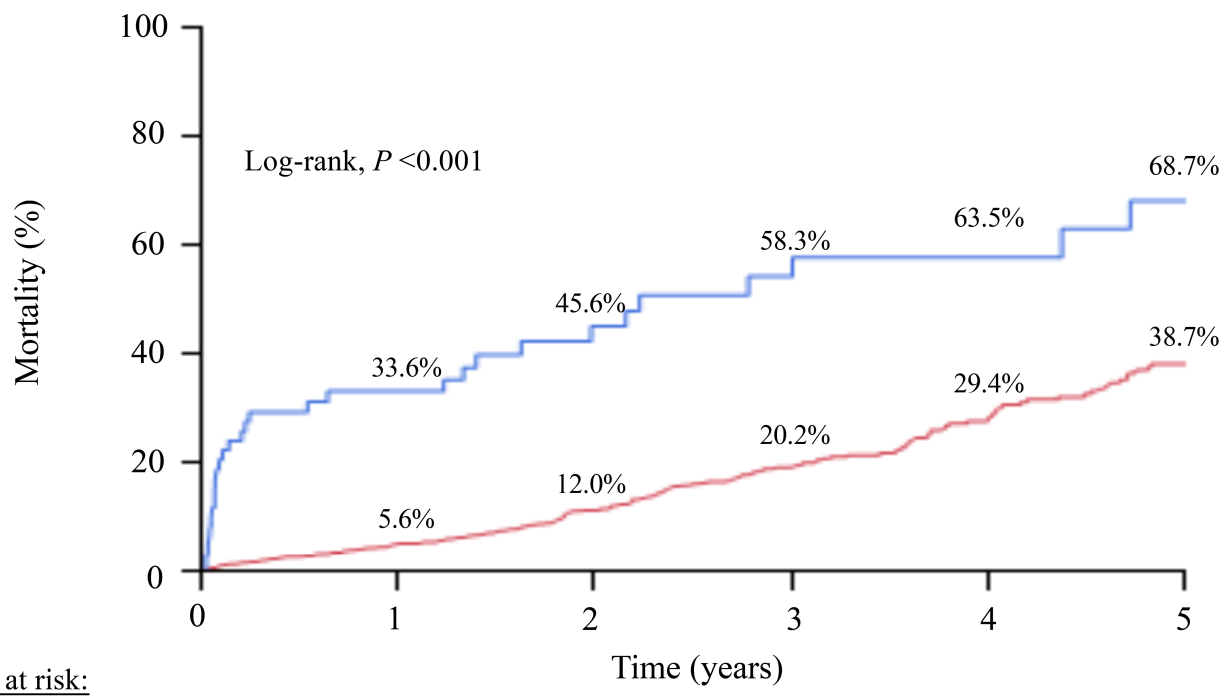

Number at risk:

\begin{tabular}{|c|c|c|c|c|c|}
\hline 57 & 34 & 20 & 12 & 8 & 6 \\
\hline 1158 & 808 & 491 & 285 & 163 & 91 \\
\hline
\end{tabular}




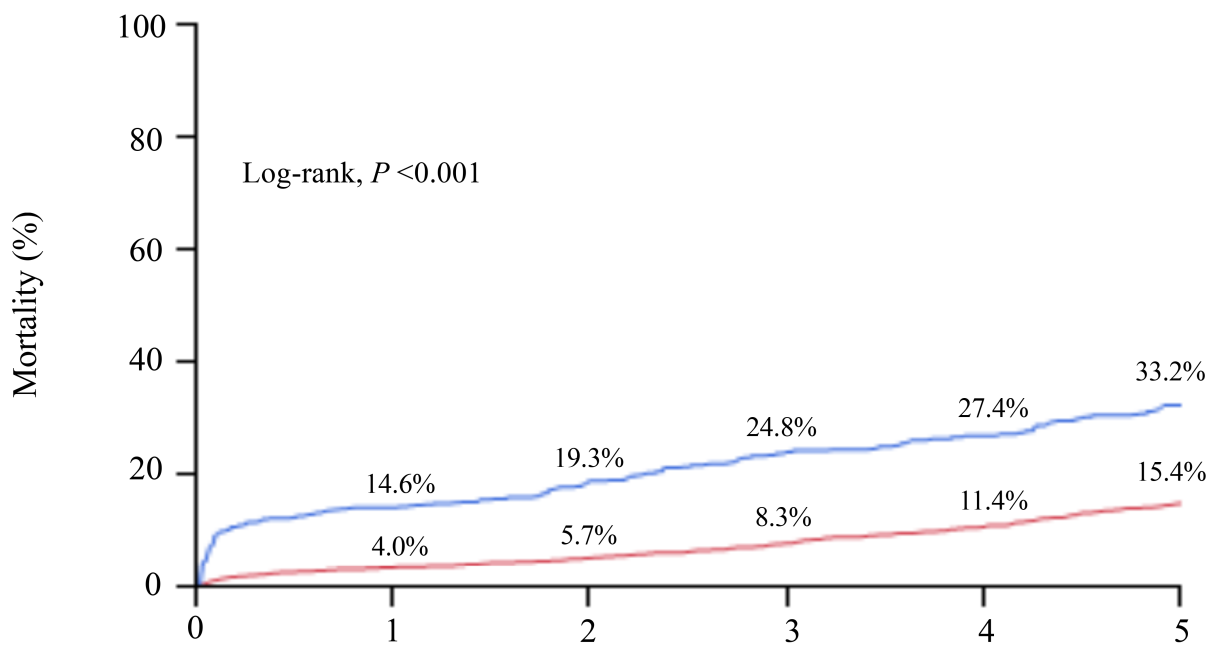

$\underline{\text { Number at risk: }}$

Time (years)

\begin{tabular}{c|c|c|c|c|c|c|}
\multirow{2}{*}{ AKI } & 549 & 441 & 383 & 307 & 254 & 179 \\
\cline { 2 - 7 } Non-AKI & 2791 & 2479 & 2173 & 1833 & 1476 & 1110 \\
\cline { 2 - 7 } & & &
\end{tabular}




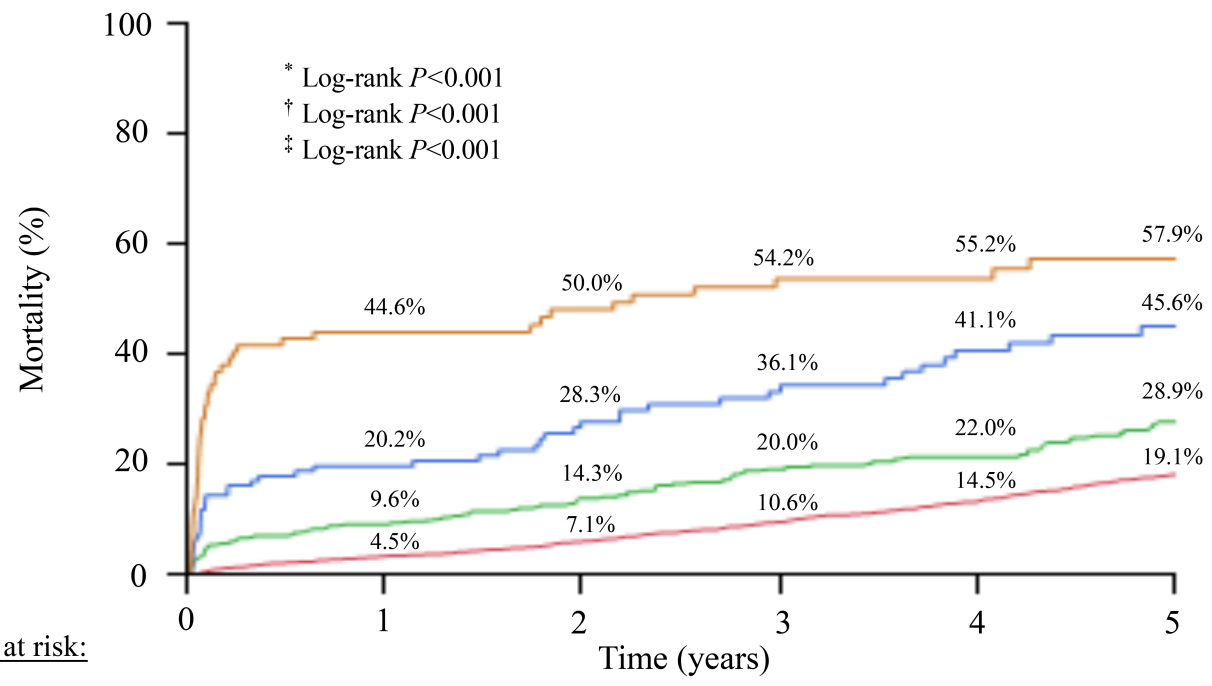

\begin{tabular}{r|c|c|c|c|c|c|}
\cline { 2 - 6 } AKI grade3 & 83 & 45 & 38 & 31 & 26 & 19 \\
\cline { 2 - 7 } AKI grade2 & 114 & 85 & 69 & 55 & 45 & 32 \\
\cline { 2 - 7 } AKI grade1 & 409 & 345 & 296 & 234 & 191 & 134 \\
\cline { 2 - 7 } Non-AKI & 3949 & 3287 & 2664 & 2118 & 1639 & 1201 \\
\cline { 2 - 7 } & & &
\end{tabular}




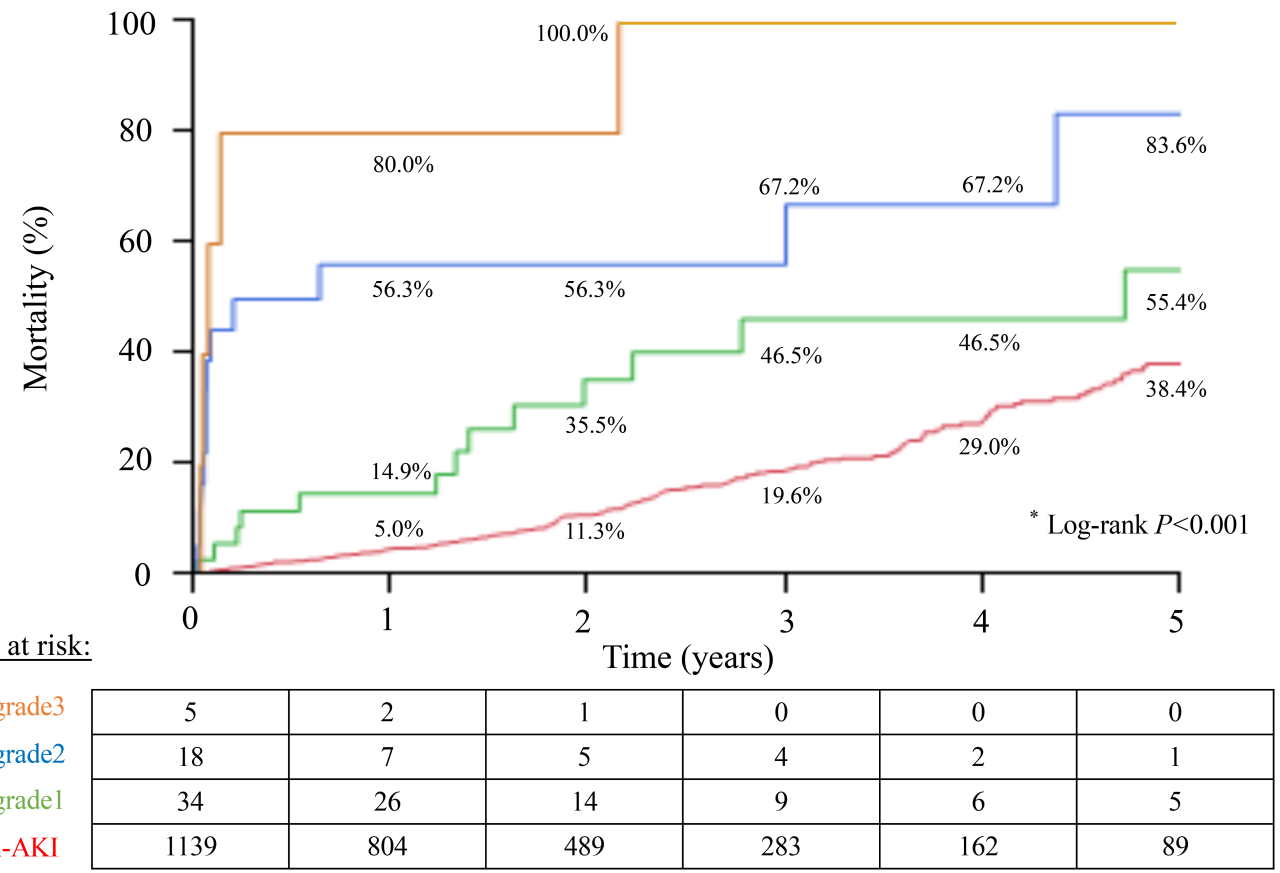




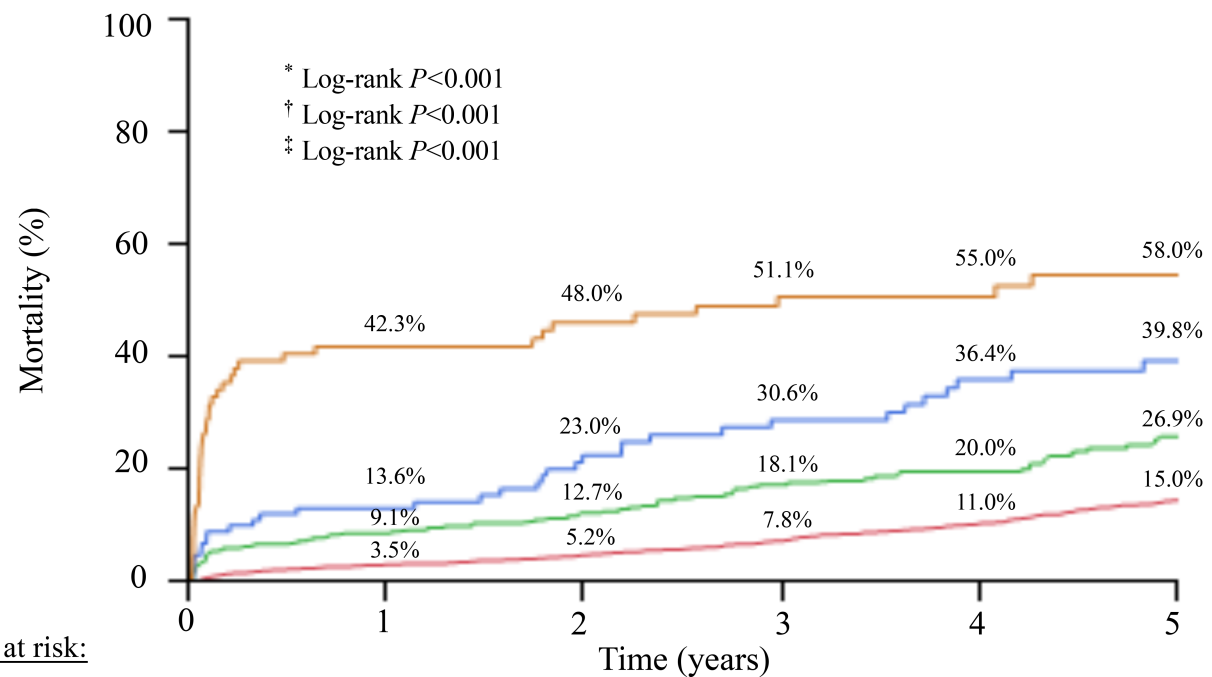

Number at risk:

Time (years)

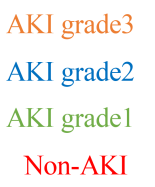

\begin{tabular}{|c|c|c|c|c|c|}
\hline 78 & 44 & 37 & 31 & 26 & 19 \\
\hline 96 & 78 & 64 & 51 & 43 & 31 \\
\hline 375 & 319 & 282 & 225 & 185 & 129 \\
\hline 2766 & 2469 & 2163 & 1823 & 1466 & 1100 \\
\hline
\end{tabular}




\begin{tabular}{cccc:c}
\hline & $\underline{\mathrm{HR}}$ & $\underline{95 \% \mathrm{CI}}$ & $\underline{\mathrm{P}-\mathrm{value}}$ & \\
$\begin{array}{c}\text { AKI grade 1 } \\
\text { (vs. non-AKI) }\end{array}$ & 1.58 & $1.20,2.08$ & 0.002 & \\
$\begin{array}{c}\text { AKI grade 2 } \\
\text { (vs. non-AKI) }\end{array}$ & 3.27 & $2.09,5.06$ & $<0.001$ & \\
$\begin{array}{c}\text { AKI grade 3 } \\
\text { (vs. non-AKI) }\end{array}$ & 4.82 & $2.93,8.04$ & $<0.001$ & \\
\hline & & & Adjusted hazard ratio
\end{tabular}

